\title{
Answering Key Global IT Management Concerns Through IT Governance and Management Processes: A COBIT 5 View
}

\author{
Tim Huygh \\ University of Antwerp, \\ Antwerp, Belgium \\ Tim.huygh@uantwerpen.be \\ Anant Joshi \\ Maastricht University, \\ Maastricht, The Netherlands \\ A.joshi@maastrichtuniversity.nl
}

\author{
Steven De Haes \\ University of Antwerp, \\ Antwerp, Belgium \\ Steven.dehaes@uantwerpen.be \\ Wim Van Grembergen \\ University of Antwerp, \\ Antwerp, Belgium \\ Wim.vangrembergen@uantwerpen.be
}

\begin{abstract}
Drawing on the COBIT 5 framework, this research presents the results of an analysis into which governance and management of IT processes are leveraged in practice for answering two key global IT management concerns: alignment and security. For practice, this research specifically sheds light on which governance and management of IT processes appear to be most important for explaining the achievement of alignment and security. Practitioners can therefore use these results as a benchmark to answer these concerns.
\end{abstract}

\section{Introduction}

Following a growing dependency on IT, an increased focus on the business value and risks of digital assets lead to an increased interest in the governance and management of these assets [1]. Over time, scholars have provided insights in how the governance and management of IT can be implemented in an organization. The contemporary view is that this can be achieved by implementing a holistic set of structures, processes, and relational mechanisms [2] [5]. The leading practitioner good-practices framework for the governance and management of IT, COBIT 5, builds on these ideas by specifying a holistic set of seven enablers that should be considered when implementing the governance and management of IT [6]. One of these enablers in particular, the process enabler, is generally considered to be very effective, as well as being the most difficult for organizations to implement [2]. Recognizing this, ISACA started with fully developing the process enabler before introducing the COBIT 5 product suite, while some other enablers are currently still in the development phase.
An issue that is particularly interesting for practitioners is the ability to identify important governance and management of IT processes that help explain the achievement of desirable IT governance and management outcomes. Drawing on the process enabler of the COBIT 5 framework, this research presents the results of such an inquiry for two desirable IT governance outcomes that are considered to be very important in practice: i.e. alignment and security. Indeed, these were the top 2 global IT management concerns for 2015 as identified by CIONET [7]. This research applies a penalized regression approach (i.e. lasso estimation) to achieve its objectives. The goal of applying this technique is to identify those governance and management of IT processes that appear to be most important in practice for explaining the achievement of alignment and security. In summary, this research is guided by the following research question: "Which governance and management of IT processes appear to be most important in practice for explaining the achievement of alignment and security objectives?"

The remainder of this paper is structured as follows. The second section contains the theoretical background to this research. First, IT governance and the COBIT 5 framework are presented. After that, the two key global IT management concerns (i.e. alignment and security) are briefly introduced. This section then ends with introducing the underlying conceptual model that drives this research. The third section presents the research methodology. More specifically, the sample is introduced (by means of descriptive statistics), as well as the statistical approach that is leveraged to meet the research objectives. Section 4 presents the main results and a 
discussion. The fifth section contains some concluding remarks and the limitations and opportunities for future research. Finally, the sixth section discusses the research implications.

\section{Theoretical background}

\subsection{IT governance and the COBIT 5 framework}

Enterprise governance of IT (EGIT), or mainly referred to as 'IT governance' is an integral part of corporate governance. Its focus is on governing ITrelated assets [3]. It can be implemented by establishing structures, processes, and relational mechanisms to govern IT assets, thereby achieving strong business/IT alignment, and ultimately improving the return on IT-enabled investments [1]. Consistent with this scope, De Haes \& Van Grembergen [8, p. 3] define enterprise governance of IT as "an integral part of corporate governance [that] addresses the definition and implementation of processes, structures and relational mechanisms in the organization that enable both business and IT people to execute their responsibilities in support of business/IT alignment and the creation of business value from IT-enabled business investments."

Guidelines on how IT governance can be implemented have emerged from academia (e.g. [2]-[5], [9], [10]). It is always acknowledged that successful implementation of IT governance is complex and warrants robust guidelines that can help firms in this task. To this extent, literature has also shown a significant role of best practice-based IT governance frameworks and standards in implementing effective IT governance practices [11]. In the practitioner area, the most extensive framework that can be used as a toolkit for enterprise governance and management of IT is Control Objectives in Information and Related Technologies (COBIT), developed by ISACA [6]. This framework is currently in its fifth edition and is centered around seven enablers for the governance and management of IT, which are interconnected, and should all be considered when implementing IT governance. Enablers in COBIT 5 are defined as: "[...] factors that, individually and collectively, influence whether something will work - in this case, governance and management of enterprise IT" [6, p. 27]. The following seven enablers are part of COBIT 5: Principles, policies and frameworks (e.g. acceptable

\footnotetext{
${ }^{1}$ For a detailed discussion on each of the enablers, the reader is referred to the COBIT 5 framework.
}

use policies); processes (e.g. portfolio management); organizational structures (e.g. IT steering committees); culture, ethics and behavior (e.g. tone at the top); information (e.g. quality of the IT strategy document); services, infrastructure and applications (e.g. tools to support the project management process); and people, skills and competencies (e.g. skill set of the $\mathrm{CIO})^{1}$.

This research focuses on the process enabler for two reasons. First, there are currently only two enabler guides fully developed as part of the COBIT 5 product suite: the process enabler and the information enabler. Therefore, these are the only two candidates to operationalize our research. Second, prior academic research indicates that processes are very effective IT governance mechanisms, as well as perceived to be the most difficult to implement [2]. It can therefore be argued that it is of particular importance for practice to understand which governance and management of IT processes prove to be important in achieving certain desirable IT governance outcomes.

COBIT 5 does provide such guidance under the form of a 'processes to IT-related goals mapping table'. This table is proposed to be generic and was originally constructed based on the results of a survey targeted at 142 experts, of which 52 responses were deemed useful. The experts were asked to rate the perceived impact of the processes for each of the IT-related goals. As these experts were asked for their opinion on "how it should be", empirical research about which processes are most important in achieving a certain ITrelated goal, using data from real organizations, can provide an interesting benchmark for organizational decision-makers in the realm of the governance and management of IT.

In the process enabler, COBIT identifies 37 processes spread over one governance and four management domains. The governance domain covers processes that are the board's responsibilities in IT (e.g. risk appetite). In the management area, four domains of processes are defined: Align, Plan, Organize (APO), Build, Acquire and Implement (BAI), Deliver, Service and Support (DSS) and Monitor, Evaluate and Assess (MEA).

\subsection{Key global IT management concerns}

\subsubsection{Business/IT alignment}


Business/IT alignment was the \#1 global IT management concern for 2015. Even more so, it has been a top 3 IT management concern since 2004 [7]. The alignment between business and IT was first clearly described by Henderson and Venkatraman [12], by means of their Strategic Alignment Model (SAM) (Figure 1). These authors positioned the concept as the fit and integration among four components: business strategy, IT strategy, business infrastructure and processes, and IT infrastructure and processes.

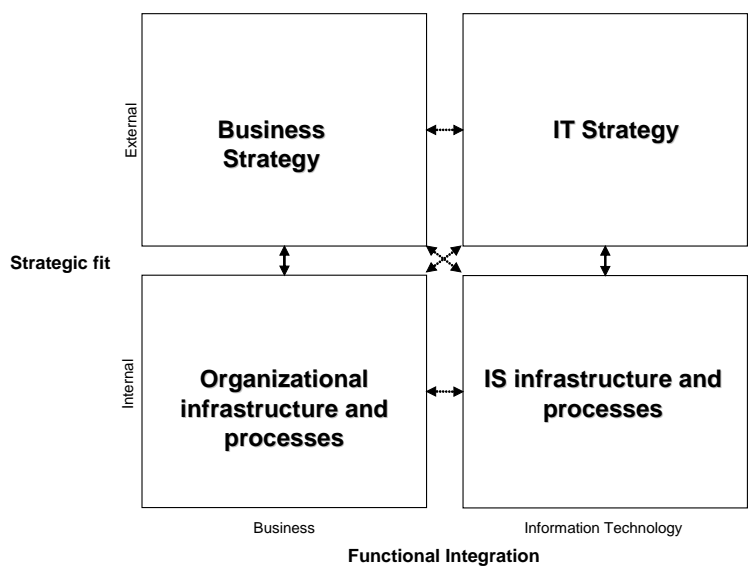

Figure 1. Strategic Alignment Model [12]

The SAM is based on two building blocks: 'strategic fit' and 'functional integration'. For IT, strategic fit is the vertical integration between IT strategy (external domain) and IT infrastructure and processes (internal domain). Strategic fit is of course equally relevant in the business domain. Two types of functional integration exist: strategic and operational integration. Strategic integration is the horizontal link between business strategy and IT strategy, reflecting the external components which are important for many companies as IT emerged as a source of strategic advantage. Operational integration covers the internal domain and deals with the link between organizational infrastructure and processes and IT infrastructure and processes.

\subsubsection{Information security}

Security was the \#2 global IT management concern for 2015. It made a quick rise, but has been a top 10 global IT management concern every year since 2004 [7]. The rise of security as a top IT management concern should be no surprise, as more and more (sensitive) data is stored in the contemporary business environment than ever before. Additionally, emerging technologies like cloud computing are finding their way to common business practice, but are nevertheless raising security awareness, certainly in the context of existing and new privacy-related laws and regulations (Sarbanes-Oxley Act and general data protection regulation in Europe).

The "CIA triangle" may very well be one of the most well-known concepts in the realm of information security [13]. This concepts refers to the three general security objectives: confidentiality, integrity, and availability [14]. In line with this, ISO/IEC formally defines information security as "the preservation of the confidentiality, integrity, and availability of information" in the context of their standard for information security management [15, p. 1].

\subsection{Conceptual model}

The aim of this paper at the conceptual level is to identify those governance and management of IT processes that appear to be most important in practice for explaining the achievement of two specifically selected key IT management concerns: alignment and security. Both the independent and the dependent constructs are operationalized through COBIT 5 (i.e. the governance and management of IT processes from the COBIT 5 process enabler as independent variables, and the two COBIT 5 IT-related goals that best map to these important concerns of alignment and security as dependent variables). The conceptual model and operationalization driving this research is presented visually in Figure 2.

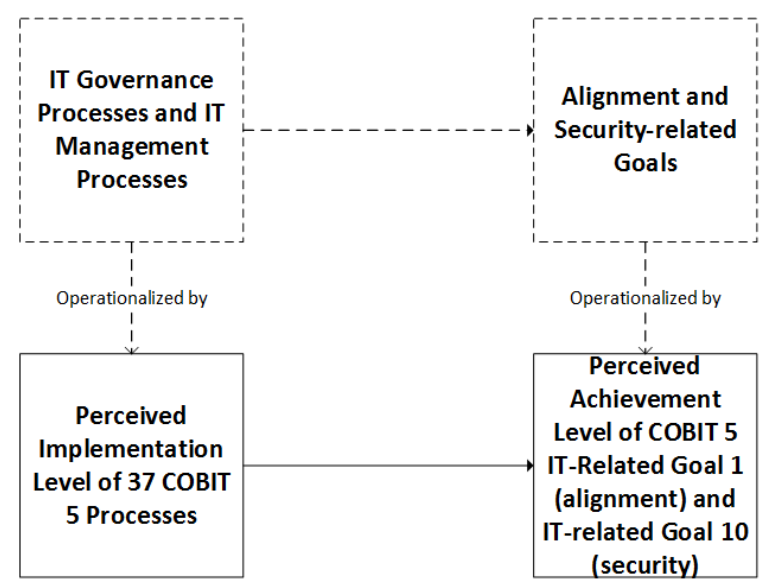

Figure 2. Conceptual model and operationalization

The 37 COBIT 5 governance and management of IT processes that will serve as candidate independent variables are measured on a 5-point ordinal scale ranging from "not implemented" to "fully implemented". The 2 IT-related goals that best map to 
the two key global IT management concerns of alignment and security, which will be used as dependent variables in this research, are measured on a 5-point ordinal scale ranging from "not achieved" to "fully achieved". Both scales are constructed to be equidistant.

\section{Research methodology}

\subsection{Sample}

The dataset for this research project was collected through an online survey between $24^{\text {th }}$ of July and $1^{\text {st }}$ of September, 2014. Business, IT, and audit representatives were solicited through local ISACA chapters. All descriptions provided in the survey were based on COBIT 5, but expressed in a way that prior knowledge of COBIT 5 was not required. The online survey captured, among other things, the respondents' perceived assessment of the implementation status of the 37 COBIT 5 processes and their perceived achievement of the COBIT 5 IT-related goals. In total 896 respondents completed the survey, of which 881 were accepted as complete responses for the final analysis.

Over the following tables, we present some sample demographics. Table 1 presents the distribution of the industry IT strategic role in the sample, a classification which is based on Chatterjee et al. [16], who proposed that industries can be classified in three groups according to the strategic role that IT plays for the industries within a group. Automate industries replace human labor by automating business processes (e.g. metal manufacturing), informate industries provide data/information to empower management and employees (e.g. food services), and transform industries fundamentally alter traditional ways of doing business by redefining business processes and relationships (e.g. airlines). Table 2 presents the distribution of firm size in the sample. Table 3 shows the distribution of geographical location of the firms in the sample. Finally, Table 4 shows the distribution of respondent functional role in the sample. In summary, the sample provides a good balance in terms of firm size, geographic location of the firm, and firm IT strategic role. Business respondents are however somewhat under-represented compared to the other two respondent functional roles.

Table 1. Demographics: Organization IT strategic

\begin{tabular}{|l|c|c|}
\multicolumn{1}{c}{} & role $(\mathbf{N}=\mathbf{8 8 1})$ & \multicolumn{1}{c|}{ Percent } \\
\cline { 2 - 3 } \multicolumn{1}{c|}{ Frequency } & 18.7 \\
\hline Automate & 165 &
\end{tabular}

\begin{tabular}{|l|l|l|}
\hline Informate & 374 & 42.5 \\
\hline Transform & 342 & 38.8 \\
\hline
\end{tabular}

Table 2. Demographics: Firm size $(\mathrm{N}=\mathbf{8 8 1})$ Frequency Percent

\begin{tabular}{|l|l|l|}
\hline $\begin{array}{l}\text { Fewer than } 50 \\
\text { employees }\end{array}$ & 44 & 5.0 \\
\hline $\mathbf{5 0 - 1 4 9}$ employees & 32 & 3.6 \\
\hline $\mathbf{1 5 0 - 4 9 9}$ employees & 127 & 14.4 \\
\hline $\mathbf{5 0 0 - 1 , 4 9 9}$ employees & 146 & 16.6 \\
\hline $\mathbf{1 , 5 0 0 - 4 , 9 9 9}$ employees & 174 & 19.8 \\
\hline $\mathbf{5 , 0 0 0 - 9 , 9 9 9}$ employees & 108 & 12.3 \\
\hline $\mathbf{1 0 , 0 0 0 - 1 4 , 9 9 9}$ employees & 55 & 6.2 \\
\hline $\begin{array}{l}\mathbf{1 5 , 0 0 0} \text { or more } \\
\text { employees }\end{array}$ & 195 & 22.1 \\
\hline
\end{tabular}

Table 3. Demographics: Region of the organization $(\mathrm{N}=\mathbf{8 8 1})$

\begin{tabular}{|l|l|l|}
\multicolumn{2}{c}{ organization $(\mathbf{N}=881)$} \\
\hline Africa & 81 & 9.2 \\
\hline Asia & 179 & 20.3 \\
\hline Caribbean & 3 & 0.3 \\
\hline $\begin{array}{l}\text { Central } \\
\text { America }\end{array}$ & 6 & 0.7 \\
\hline Europe & 209 & 23.7 \\
\hline Middle East & 50 & 5.7 \\
\hline $\begin{array}{l}\text { North } \\
\text { America }\end{array}$ & 274 & 31.1 \\
\hline Oceania & 27 & 3.1 \\
\hline $\begin{array}{l}\text { South } \\
\text { America }\end{array}$ & 52 & 5.9 \\
\hline
\end{tabular}

Table 4. Demographics: Respondent functional role $(\mathrm{N}=867)$

\begin{tabular}{|l|l|l|}
\multicolumn{1}{l|}{} & Frequency & Percent \\
\hline Business & 59 & 6.7 \\
\hline IT & 394 & 44.7 \\
\hline $\begin{array}{l}\text { Audit, risk, and } \\
\text { compliance }\end{array}$ & 414 & 47.0 \\
\hline
\end{tabular}

Table 5 presents descriptive statistics for the 37 COBIT 5 processes, which will be used as the set of candidate independent variables in this research. Table 6 contains the same information, but this time for the two COBIT 5 IT-related goals that are used to operationalize the two global IT management concerns in this research, i.e. alignment and security.

Table 5. Descriptives for the 37 COBIT 5

\begin{tabular}{|l|l|l|l|}
\multicolumn{1}{c}{} & processes (independents) \\
\cline { 2 - 4 } \multicolumn{1}{c|}{} & $\mathrm{N}$ & Mean & $\begin{array}{l}\text { Std. } \\
\text { Deviation }\end{array}$ \\
\hline EDM01 & 866 & 3.10 & 1.184 \\
\hline EDM02 & 857 & 3.03 & 1.113 \\
\hline
\end{tabular}




\begin{tabular}{|l|l|l|l|}
\hline EDM03 & 866 & 3.13 & 1.155 \\
\hline EDM04 & 863 & 3.15 & 1.063 \\
\hline EDM05 & 858 & 3.19 & 1.145 \\
\hline APO01 & 859 & 3.38 & 1.070 \\
\hline APO02 & 865 & 3.50 & 1.052 \\
\hline APO03 & 858 & 3.32 & 1.113 \\
\hline APO04 & 854 & 2.93 & 1.145 \\
\hline APO05 & 848 & 3.27 & 1.085 \\
\hline APO06 & 859 & 3.86 & 1.001 \\
\hline APO07 & 860 & 3.64 & 1.011 \\
\hline APO08 & 858 & 3.41 & 1.063 \\
\hline APO09 & 860 & 3.49 & 1.105 \\
\hline APO10 & 856 & 3.61 & 1.027 \\
\hline APO11 & 859 & 3.33 & 1.073 \\
\hline APO12 & 867 & 3.39 & 1.074 \\
\hline APO13 & 869 & 3.78 & 1.012 \\
\hline BAI01 & 863 & 3.60 & 0.997 \\
\hline BAI02 & 860 & 3.38 & 1.070 \\
\hline BAI03 & 854 & 3.39 & 1.037 \\
\hline BAI04 & 860 & 3.51 & 1.031 \\
\hline BAI05 & 850 & 3.17 & 1.128 \\
\hline BAI06 & 862 & 3.48 & 1.045 \\
\hline BAI07 & 857 & 3.34 & 1.070 \\
\hline BAI08 & 860 & 3.04 & 1.105 \\
\hline BAI09 & 864 & 3.50 & 1.055 \\
\hline BAI0 & 858 & 3.40 & 1.083 \\
\hline DSS01 & 864 & 3.78 & 0.955 \\
\hline DSS02 & 863 & 3.84 & 0.973 \\
\hline DSS03 & 861 & 3.61 & 1.011 \\
\hline DSS04 & 859 & 3.59 & 1.051 \\
\hline DSS05 & 860 & 3.70 & 1.019 \\
\hline DSS06 & 855 & 3.34 & 1.071 \\
\hline MEA01 & 859 & 3.26 & 1.108 \\
\hline MEA02 & 857 & 3.38 & 1.142 \\
\hline MEA03 & 855 & 3.49 & 1.111 \\
\hline & & & \\
\hline
\end{tabular}

Table 6. Descriptives for the two COBIT 5 ITrelated goals (dependents)

\begin{tabular}{|lll|l|l|}
\cline { 3 - 5 } \multicolumn{1}{c|}{} & $\mathrm{N}$ & Mean & $\begin{array}{l}\text { Std. } \\
\text { Deviation }\end{array}$ \\
\hline $\begin{array}{l}\text { IT-related goal } \\
\text { (alignment) }\end{array}$ & 01 & 868 & 3.42 & 1.006 \\
\hline $\begin{array}{l}\text { IT-related goal } \\
\text { (security) }\end{array}$ & 10 & 872 & 3.66 & 1.000 \\
\hline
\end{tabular}

\subsection{Statistical approach}

Multiple regression is a very popular first-generation technique when the purpose is to examine the effect of independent variables on a dependent variable. The traditional ordinary least squares (OLS) approach to regression dates back to the late 1800's. With advancement in computing technology came advances in regression techniques. For instance, as modern data analysis often deals with high-dimensional data (i.e. a lot of independent variables), statisticians went on a quest for regression techniques that are better equipped to handling such data. This then resulted in a number of more modern regression techniques.

Often, researchers are interested in selecting a set of useful independent variables from a larger pool of candidates. When all independent variables are on the same scale (by default or after standardization), the relative importance of each variable can also be assessed. In our dataset, the pool of candidate independent variables (i.e. the 37 COBIT 5 governance and management of IT processes) are on the same scale (i.e. 5-point ordinal scale from "not implemented to "fully implemented", constructed to be equidistant). Popular so-called "variable selection" approaches for traditional OLS-based multiple regression include stepwise regression and all subsets regression. The latter technique is often considered to be the better choice of the two, as it ensures that every possible model is evaluated. This can however become a problem in terms of computing time when dealing with high-dimensional data. These traditional variable selection methods either include or exclude a predictor from the model. Furthermore, these methods are based on a certain criterion (e.g. adjusted $\mathrm{R}^{2}$, BIC, or Mallow's $C_{p}$ ) that allows to compare global model fit between different models (i.e. containing a different set of independent variables) on the same data, but during the actual regression estimation itself, there is no way to perform variable selection in traditional OLS-based regression.

Penalized estimation methods are a set of modern regression techniques that result in shrinkage effects on all or some of the predictors. These methods were initially developed to deal with high-dimensional data (where there is a realistic chance of multicollinearity problems among possible independent variables). Nevertheless, in absence of multicollinearity problems, these techniques are also sometimes applied to reduce the mean squared error (MSE), i.e. to increase predictive performance of the model. Two popular techniques in this area are (1) ridge regression, initially described by Hoerl \& Kennard [17], and (2) lasso estimation as developed by Tibshirani [18]. In fact, it can be proven that ridge and lasso are both of the same family of techniques (i.e. penalized estimation methods). The main difference lies in the fact that ridge regression only performs shrinkage towards zero, while lasso is able to set some coefficients exactly to zero. Therefore, the lasso method performs model estimation and variable 
selection simultaneously. For this reason, the lasso estimation method better suits our research objective. Penalized estimation techniques, like ridge and lasso, include a shrinkage parameter, $\lambda$, that produces coefficients that are very close to the OLS coefficients when it is zero, while shrinkage increases with $\lambda$. With penalized estimation methods, cross-validation may be used to determine a data-driven value for the shrinkage parameter $\lambda$. In this research, we will use this approach, specifically 10 -fold cross validation.

For this research, the statistical software RStudio (version 1.0.136) based on the $\mathrm{R}$ environment $(\mathrm{R}$ version 3.3.1) is used. Penalized estimation by means of lasso is applied using the glmnet function from the glmnet package. Additionally, the function cv.glmnet from the same package is used to determine a datadriven value of the shrinkage parameter $\lambda$.

\section{Results}

\subsection{Business/IT alignment}

To operationalize the alignment concern, we use COBIT 5's IT-related goal 1, "alignment of IT and business strategy" as the dependent variable. The full pool of 37 COBIT 5 governance and management of IT processes is used as candidate independent variables, as input to model estimation using the lasso estimator. As previously discussed, 10-fold crossvalidation is used to determine a data-driven value for the shrinkage parameter. The coefficients of the final model are displayed in Table 7, ordered from highest to lowest (this can be seen as relative importance). Processes that are not included in this table have their coefficients put to zero during lasso estimation (and are therefore considered to be unimportant in explaining this IT-related goal). We can also see that all coefficients are positive, meaning that they all have a positive contribution to the achievement level of the business/IT alignment goal.

Table 7. Coefficients for alignment goal

\begin{tabular}{|l|l|}
\hline APO02 & 0.1805817988 \\
\hline DSS04 & 0.0885481268 \\
\hline BAI03 & 0.0851535500 \\
\hline EDM02 & 0.0841813088 \\
\hline EDM03 & 0.0578147244 \\
\hline EDM05 & 0.0556797685 \\
\hline MEA02 & 0.0518988277 \\
\hline APO04 & 0.0516067420 \\
\hline APO08 & 0.0511915728 \\
\hline DSS02 & 0.0470982856 \\
\hline APO13 & 0.0274281585 \\
\hline
\end{tabular}

\begin{tabular}{|l|l|}
\hline BAI02 & 0.0217119089 \\
\hline EDM01 & 0.0146373099 \\
\hline APO01 & 0.0060540300 \\
\hline MEA03 & 0.0005888107 \\
\hline
\end{tabular}

\subsection{Information security}

To operationalize the security concern, we use COBIT 5's IT-related goal 10, "security of information, processing infrastructure, and applications" as the dependent variable. Similarly, the full pool of 37 COBIT 5 processes is used here as well as input to the model estimation, and 10-fold cross-validation is used to determine a data-driven value for the shrinkage parameter that will be used during lasso estimation. The coefficients of the final model for this goal are displayed in Table 8, ordered from highest to lowest (this can be seen as relative importance). Processes that are not included in this table have their coefficients put to zero during lasso estimation (and are therefore considered to be unimportant in explaining this IT-related goal). Here too we see that all coefficients are positive, meaning that they all have a positive contribution to the achievement level of the information security goal.

Table 8. Coefficients for security goal

\begin{tabular}{|l|l|}
\hline APO13 & 0.311637725 \\
\hline DSS05 & 0.229810513 \\
\hline MEA03 & 0.093197552 \\
\hline DSS01 & 0.084752737 \\
\hline BAI03 & 0.048694377 \\
\hline BAI09 & 0.034480824 \\
\hline BAI06 & 0.029030067 \\
\hline APO07 & 0.015418160 \\
\hline EDM02 & 0.007044095 \\
\hline DSS04 & 0.004335104 \\
\hline
\end{tabular}

\subsection{Discussion}

For the business/IT alignment concern, we found that 15 out of 37 processes remained in the final model, i.e. 22 processes had their coefficients being set to zero during lasso estimation and were therefore deemed unimportant in explaining the achievement of the business/IT alignment goal. To explain the processes that remained in the final model, we mapped them to the dimensions of the SAM (Figure 3). For instance, the process with the greatest relative importance is APO02 "manage strategy". COBIT 5 states that the purpose of this process is to "align strategic IT plans with business objectives [...]" [19, p. 57]. Using the SAM, this process therefore clearly works on the horizontal link between business strategy and IT 
strategy (i.e. functional integration, strategic). As a second example, DSS04 “manage continuity” is about aligning business and IT operations in such a way that ultimately the continuity of critical business operations is ensured (e.g. through the availability of information, which directly links to the next issue of information security). This process can therefore be mapped to the operational functional integration dimension of the SAM.

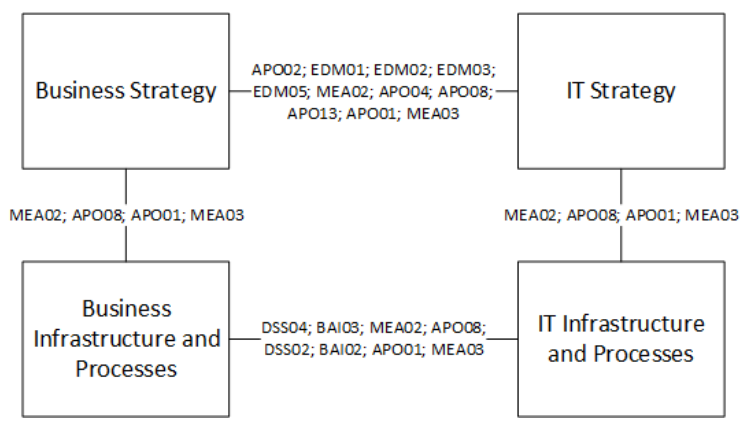

Figure 3. Map processes for alignment goal to SAM

For the information security concern, only 10 out of 37 processes were kept in the final model, meaning that 27 processes were deemed unimportant in explaining the achievement of the information security goal. To explain the processes that remained in the final model, we mapped them to the CIA triangle (Table 9). For instance, the process with the greatest relative importance in achieving the information security goal is APO13 "manage security". COBIT 5 describes this process as one that defines, operates, and monitors a system for information security management. In the process description, the reader is also directly referred to ISO/IEC 27002, the standard for information security management, for further guidance. It is clear that this generic process therefore influences all three facets of the CIA triangle.

The process with the second greatest relative importance in achieving the information security goal is DSS05 "manage security services", a process that can be seen as the operational counterpart of APO13. Therefore, DSS05 also influences all three facets of the CIA triangle.

Table 9. Map processes for security goal to CIA triangle

\begin{tabular}{|l|c|c|c|}
\cline { 2 - 4 } \multicolumn{1}{c|}{} & $\mathrm{C}$ & $\mathrm{I}$ & $\mathrm{A}$ \\
\hline APO13 & $\mathrm{X}$ & $\mathrm{X}$ & $\mathrm{X}$ \\
\hline DSS05 & $\mathrm{X}$ & $\mathrm{X}$ & $\mathrm{X}$ \\
\hline MEA03 & $\mathrm{X}$ & $\mathrm{X}$ & $\mathrm{X}$ \\
\hline DSS01 & & & $\mathrm{X}$ \\
\hline BAI03 & $\mathrm{X}$ & $\mathrm{X}$ & $\mathrm{X}$ \\
\hline
\end{tabular}

\begin{tabular}{|l|c|c|c|}
\hline BAI09 & & & $\mathrm{X}$ \\
\hline BAI06 & $\mathrm{X}$ & $\mathrm{X}$ & $\mathrm{X}$ \\
\hline APO07 & & & $\mathrm{X}$ \\
\hline EDM02 & $\mathrm{X}$ & $\mathrm{X}$ & $\mathrm{X}$ \\
\hline DSS04 & & & $\mathrm{X}$ \\
\hline
\end{tabular}

Finally, we can compare the conceptual mapping provided in COBIT 5 with our empirical results. As previously discussed, COBIT 5 provides guidance in the form of a mapping table between processes and ITrelated goals. Using this mapping table, practitioners can see which governance and management of IT processes contribute to the achievement of a certain IT-related goal, and the strength of this relationship (' $\mathrm{P}$ ' stands for primary contribution, while ' $\mathrm{S}$ ' stands for secondary contribution). Comparing COBIT 5’s conceptual mapping with our empirical results enables us to check if the conceptual description of which processes contribute to the achievement of a certain IT-related goal appear to reflect the reality of practice (Table 10).

Upon studying this table, there appear to be some differences between the conceptual mapping as provided in COBIT 5 and our empirical results. It can for instance be seen that, for the business/IT alignment concern, the conceptual mapping prescribed 12 processes that cannot be confirmed by our empirical results. When only looking at the primary links as put forward by COBIT 5, 4 out of 10 links cannot be empirically confirmed. Our empirical results also identify 4 important processes that are not identified in COBIT 5's conceptual mapping. A similar observation exists for the information security concern, where 2 out of 5 primary links as conceptually mapped by COBIT 5 are not empirically confirmed in this study. Here too, 2 processes are empirically identified that were not conceptually mapped in COBIT 5.

It should be noted however, that COBIT 5 warns about mechanistically using the goals cascade, stating that it “does not contain the universal truth" [19, p. 16]. It is specifically acknowledged in COBIT 5 that the goals cascade in its current form does not account for different contexts, rather, it presents a sort of common denominator. Additionally, COBIT acknowledges that is only uses two levels of importance (viz. primary and secondary), while in reality this will be more of a continuum. While this research in its current form also does not distinguish between different contexts or contingencies, it does present the relative importance more on a continuum than the COBIT conceptual mapping does. 
Table 10. Compare COBIT 5 conceptual mapping and empirical results

\begin{tabular}{|c|c|c|c|c|}
\hline & \multicolumn{2}{|c|}{ Business/IT alignment } & \multicolumn{2}{|c|}{ Information security } \\
\hline & COBIT mapping & Empirical & COBIT mapping & Empirical \\
\hline EDM01 & $\mathrm{P}$ & $\mathrm{X}$ & $\mathrm{S}$ & \\
\hline EDM02 & $\mathrm{P}$ & $\mathrm{X}$ & & $\mathrm{X}$ \\
\hline EDM03 & $\mathrm{S}$ & $\mathrm{X}$ & $\mathrm{P}$ & \\
\hline EDM04 & $\mathrm{S}$ & & & \\
\hline EDM05 & $\mathrm{S}$ & $\mathrm{X}$ & & \\
\hline APO01 & $\mathrm{P}$ & $\mathrm{X}$ & $\mathrm{S}$ & \\
\hline APO02 & $\mathrm{P}$ & $\mathrm{X}$ & & \\
\hline APO03 & $\mathrm{P}$ & & $\mathrm{S}$ & \\
\hline APO04 & $\mathrm{S}$ & $\mathrm{X}$ & & \\
\hline APO05 & $\mathrm{P}$ & & & \\
\hline APO06 & $\mathrm{S}$ & & & \\
\hline APO07 & $\mathrm{P}$ & & $\mathrm{S}$ & $\mathrm{X}$ \\
\hline APO08 & $\mathrm{P}$ & $\mathrm{X}$ & & \\
\hline APO09 & $\mathrm{S}$ & & $\mathrm{S}$ & \\
\hline APO10 & & & $\mathrm{S}$ & \\
\hline APO11 & $\mathrm{S}$ & & & \\
\hline APO12 & & & $\mathrm{P}$ & \\
\hline APO13 & & $\mathrm{X}$ & $\mathrm{P}$ & $\mathrm{X}$ \\
\hline BAI01 & $\mathrm{P}$ & & & \\
\hline BAI02 & $\mathrm{P}$ & $\mathrm{X}$ & $\mathrm{S}$ & \\
\hline BAI03 & $\mathrm{S}$ & $\mathrm{X}$ & & $\mathrm{X}$ \\
\hline \multicolumn{5}{|l|}{ BAI04 } \\
\hline BAI05 & $\mathrm{S}$ & & & \\
\hline BAI06 & & & $\mathrm{P}$ & $\mathrm{X}$ \\
\hline \multicolumn{5}{|l|}{ BAI07 } \\
\hline BAI08 & $\mathrm{S}$ & & $\mathrm{S}$ & \\
\hline BAI09 & & & $\mathrm{S}$ & $\mathrm{X}$ \\
\hline BAI10 & & & $\mathrm{S}$ & \\
\hline DSS01 & & & $\mathrm{S}$ & $\mathrm{X}$ \\
\hline DSS02 & & $\mathrm{X}$ & $\mathrm{S}$ & \\
\hline \multicolumn{5}{|l|}{ DSS03 } \\
\hline DSS04 & $S$ & $\mathrm{X}$ & $\mathrm{S}$ & $\mathrm{X}$ \\
\hline DSS05 & $\mathrm{S}$ & & $\mathrm{P}$ & $\mathrm{X}$ \\
\hline DSS06 & & & $S$ & \\
\hline MEA01 & $\mathrm{S}$ & & $S$ & \\
\hline MEA02 & & $\mathrm{X}$ & $\mathrm{S}$ & \\
\hline MEA03 & & $\mathrm{X}$ & $\mathrm{S}$ & $\mathrm{X}$ \\
\hline
\end{tabular}

\section{Conclusions, limitations, and opportunities for future research}

The objective of this research was to identify those governance and management of IT processes that appear to be most important in practice for explaining the achievement of two key global IT management objectives: business/IT alignment and information security. Using data from practice while drawing on the COBIT 5 framework, we were able to empirically identify those processes that best explain the achievement of each of these two objectives.

For the business/IT alignment goal, the process with the greatest contribution to its achievement appears to be APO02, "manage strategy". Unsurprisingly, the purpose of this process is to align strategic IT plans with the business objectives. Other processes with relatively high importance for explaining the achievement of the business/IT alignment goal are DSS04, BAI03, and EDM02. In total, 15 out of 37 
processes were kept in the model during lasso estimation, meaning that the other 22 processes are considered to be unimportant when it comes to explaining the achievement of the business/IT alignment goal. The processes that were kept in the model were then mapped to the dimensions of the SAM. This mapping revealed that most processes to achieve this goal are working on the external functional integration dimension, which can be seen as strategic alignment. A lot of the other processes are working on the internal functional integration. Only a minority of processes are working on the business and IT strategic fit dimensions. Nevertheless, all dimensions of the SAM can be accounted for.

For the information security goal, two processes appear to have relatively very high contributions to its achievement. These processes are APO13, "manage security", and its operational counterpart DSS05 "manage security services". Both processes indeed are the main security-related processes of the COBIT 5 process enabler. In total, 10 out of 37 processes were kept in the model during lasso estimation, meaning that the other 27 processes were deemed unimportant when it comes to explaining the achievement of the information security goal. The processes that were kept in the model were then mapped to the CIA triangle of information security. The three processes with the highest relative importance are working on all three of the facets (i.e. confidentiality, integrity, and availability).

A first clear limitation of this research is that it is essentially limited to describing the relationships between the implementation level of processes and the achievement of goals (i.e. what). Therefore, further research is needed, especially on why these processes are important for explaining these goals. In-depth case study research might therefore provide very interesting additional insights. A second limitation is that this sample is not entirely balanced in terms of firm sizes, geographic region, and respondent functional role. For the respondent functional role, especially the business respondents are under-represented in the sample. A small imbalance can also be observed in the frequency distribution of industry IT strategic role. Nevertheless, our sample is sufficiently large $(\mathrm{N}=881)$ so that this issue is by no means problematic. A third limitation is the generic approach that was used in this paper. It could make sense to split the sample in subgroups (for instance using the IT strategic role that was described in Table 1). This way, it could be investigated whether organizations with a different IT strategic dependency leverage other processes for achieving certain objectives. Finally, the fact that only the top two global
IT management concerns were used in the realm of this conference paper directly leads to the opportunity of further research into other IT management concerns or IT-related goals.

\section{Implications}

For practice, this research shed light on which governance and management of IT processes appear to be most important for explaining the achievement of alignment and security, two key global IT management concerns in 2015. Practitioners can therefore use these results as a benchmark for their organizations if they are concerned with alignment and security.

From an academic point of view, this study empirically approached the effect of certain governance and management of IT processes on the achievement of certain IT-related goals. It can also be seen as a call for further research into validating industry best-practices like the COBIT 5 framework. The method that was used in this paper can furthermore provide scholars with a rigorous way of combining model estimation and variable selection simultaneously, which can be especially useful for research projects in MIS with similar objectives as the one in this paper.

\section{References}

[1] S. De Haes and W. Van Grembergen, Enterprise governance of information technology, second edition. Springer, 2015.

[2] S. De Haes and W. Van Grembergen, “An Exploratory Study into IT Governance Implementations and its Impact on Business/IT Alignment,” Inf. Syst. Manag., vol. 26, no. 2, pp. 123-137, Apr. 2009.

[3] P. Weill and J. W. Ross, IT Governance: How Top Performers Manage IT Decision Rights for Superior Results. Harvard Business Press, 2004.

[4] A. Prasad, P. Green, and J. Heales, “On IT governance structures and their effectiveness in collaborative organizational structures," Int. J. Account. Inf. Syst., vol. 13, no. 3, pp. 199-220, Sep. 2012.

[5] R. Huang, R. W. Zmud, and R. L. Price, "Influencing the effectiveness of IT governance practices through steering committees and communication policies,” Eur. J. Inf. Syst., vol. 19, no. 3, pp. 288-302, Mar. 2010.

[6] ISACA, “COBIT 5: A Business Framework for the Governance and Management of Enterprise IT,” 2012.

[7] B. Derksen and J. Luftman, "Key European IT 
Management Trends for 2016,” 2016.

[8] W. Van Grembergen and S. De Haes, Enterprise Governance of Information Technology: Achieving Strategic Alignment and Value. Springer, 2009.

[9] R. R. Peterson, "Crafting Information Technology Governance,” Inf. Syst. Manag., vol. 21, no. 4, pp. 7-22, Sep. 2004.

[10] S. Ali and P. Green, "Effective information technology (IT) governance mechanisms: An IT outsourcing perspective,” Inf. Syst. Front., vol. 14, no. 2, pp. 179-193, Jun. 2009.

[11] S. De Haes, W. Van Grembergen, and R. S. Debreceny, "COBIT 5 and Enterprise Governance of Information Technology: Building Blocks and Research Opportunities,” J. Inf. Syst., vol. 27, no. 1, pp. 307-324, Jun. 2013.

[12] J. C. Henderson and N. Venkatraman, "Strategic alignment: leveraging information technology for transforming organizations," IBM Syst. J., vol. 32, no. 1, pp. 4-16, Jan. 1993.

[13] M. Whitman and H. Mattord, Principles of information security. Cengage Learning, 2011.

[14] International Telecommunications Union (ITU), "ITU-TX.1205: series X: data networks, open system communications and security: telecommunications security: overview of sybersecurity 2008.,” 2008.

[15] ISO/IEC, "ISO/IEC 27002: code of practice for information security management 2005.,” 2005.

[16] D. Chatterjee, V. Richardson, and R. Zmud, "Examining the Shareholder Wealth Effects of Announcements of Newly Created CIO Positions," Management Information Systems Quarterly, vol. 25, no. 1. 2001.

[17] A. E. Hoerl and R. W. Kennard, "Ridge Regression: Biased Estimation for Nonorthogonal Problems,” Technometrics, vol. 12, no. 1, pp. 5567, Feb. 1970.

[18] R. Tibshirani, “Journal Article Regression Shrinkage and Selection via the Lasso," J. R. Stat. Soc. Ser. B, vol. 58, no. 1, pp. 267-288, 1996.

[19] ISACA, “COBIT 5: Enabling Processes,” 2012. 